\title{
The Ecosystem Approach to Management in Marine Environmental Governance: Institutional interplay in the Baltic Sea Region
}

Sara Söderström and Kristine Kern

The self-archived version of this journal article is available at Linköping University Institutional Repository (DiVA):

http:/ / urn.kb.se/ resolve?urn=urn:nbn:se:liu:diva-141009

N.B.: When citing this work, cite the original publication.

Söderström, S., Kern, K., (2017), The Ecosystem Approach to Management in Marine Environmental Governance: Institutional interplay in the Baltic Sea Region, Environmental Policy and Governance. https:// doi.org/ 10.1002/ eet.1775

Original publication available at:

https:/ / doi.org/ 10.1002/ eet.1775

Copyright: Wiley: 24 months

http://eu.wiley.com/WileyCDA/ 


\title{
The Ecosystem Approach to Management in Marine Environmental Governance: Institutional Interplay in the Baltic Sea Region
}

\author{
SARA SÖDERSTRÖM * \& KRISTINE KERN **
}

*School of Natural Sciences, Technology and Environmental Studies, Södertörn University, Alfred Nobels Allé 7, 141 89, Huddinge, Sweden. Telephone: 0046 (0)8 60845 67. Fax: 0046 (0)8 6084510. sara.soderstrom@sh.se, and Department of Thematic Studies (TEMA), Linköping University, Sweden

**Leibniz Institute for Research on Society and Space (IRS), Germany

\begin{abstract}
This article focuses on the use of the Ecosystem Approach to Management (EAM) in the Baltic Sea Region (BSR). Based on selected criteria for EAM, the article traces and compares the impact of EAM on HELCOM's Baltic Sea Action Plan (BSAP), the EU Water Framework Directive (WFD), the EU Marine Strategy Framework Directive (MSFD) and the EU Maritime Spatial Planning Directive (MSPD). As the impact of the EAM on these policies varies, it is then asked how these differences can be explained. Starting from the assumption that institutional interplay determines the impact of the EAM on marine policies, the article examines how different forms of interplay (interplay through cognition, commitment and compliance) affect the spread of EAM and its implementation in the BSR. The study finds strong interplay, in particular between HELCOM's BSAP and the EU's MSFD. Although HELCOM is still an important player in marine governance in the BSR region since it includes Russia, taking over responsibilities for the implementation of EU legislation affects its independence and also has repercussions for decision-making within HELCOM.
\end{abstract}

Keywords: Ecosystem approach to management, environmental governance, Baltic Sea Action Plan, EU Water Framework Directive, EU Marine Strategy Framework Directive, EU Maritime Spatial Planning Directive

The research leading to these results has received funding from the Foundation for Baltic and East European Studies and from the European Community's Seventh Framework Programme (FP/20072013) under grant agreement $n^{\circ} 217246$ made with the joint Baltic Sea research and development programme BONUS. 


\section{Introduction}

The ecosystem approach to management (EAM) is a theoretical approach as well as a management concept for the sustainable use of natural resources. The aim of this article is to examine how this concept is applied to European marine governance, in particular in the Baltic Sea Region (BSR). The Baltic Sea environment is protected by the Helsinki Convention dating back to the 1970s, which is governed by the Helsinki Commission (HELCOM). As eight out of nine countries bordering the Baltic Sea are members of the European Union, the marine environment of the Baltic Sea is also governed by the EU. This article focuses on four policy initiatives developed by HELCOM on the one hand and the EU on the other, namely HELCOM's Baltic Sea Action Plan (BSAP), the EU Water Framework Directive (WFD), the EU Marine Strategy Framework Directive (MSFD) and the EU Maritime Spatial Planning Directive (MSPD). The four policy initiatives were chosen due to their relevance and importance as tools for marine environmental governance in the BSR. The BSAP and the three EU directives are regarded as innovative, with a strong emphasis on ecosystem-based approaches (van Leeuwen, Soma, and van Tatenhove 2015).

The aim of this article is twofold: By analysing and comparing four policy documents, the study traces and assesses the impact of the EAM on marine governance in the BSR. Each policy area is thus explored with regard to finding explicit or implicit evidence for the EAM based on a set of five criteria which altogether make up the essence of the EAM: (i) holistic approach with human inclusion, (ii) scale dependency and integration, (iii) sound science, (iv) participation and (v) adaptive management and ecosystem services. As the impact of the EAM on the four policy areas varies considerably, it is then asked how these differences can be explained. Starting from the assumption that institutional interplay determines the impact of innovative ideas (such as the EAM) on marine policies from the global to the local level, the article distinguishes three forms of interplay: interplay through cognition (in the agendasetting phase), interplay through commitment (in the decision-making phase) and interplay through compliance (in the implementation phase). The article thus fills a research gap, because there have been almost no systematic studies on the development, spread and implementation of the EAM in the BSR.

The Baltic Sea Region is an area described as 'where the east meets the west' (Tynkkynen 2014). Although the first regional seas convention (Helsinki Convention) was established here and cooperation on environmental issues has been relatively fruitful since that time, the area also has a long history of disagreement, conflict and even war. The area currently hosts both some of the richest and some of the poorest EU countries (Vangas 2010), and the ideological, economic and political legacies of the Cold War still divide the region and thus shape the conditions for environmental management (Tynkkynen 2014). Since all bordering countries, except Russia, are EU member states (Sweden, Denmark, Germany, Poland, Lithuania, Latvia, Estonia and Finland), good working conditions for environmental collaboration exist. The whole area has also been chosen as the EU's first macro-region (EU Strategy for the Baltic Sea Region), which highlights the specific conditions in and uniqueness of the region 
(Kern 2011, Gänzle and Kern 2016). Despite not being a member of the EU, Russia is a signatory to HELCOM and has thus been actively involved in various forms of environmental cooperation within the region since the 1970s. In addition to the fact that the Ukraine crisis has had negative impacts on EU-Russian relations, tensions between the framing of marine policy by the EU on the one hand and Russia on the other were evident even earlier (Gritsenko 2013).

Empirical research is based on (i) a literature review, (ii) an analysis of relevant policy documents and (iii) expert interviews. A content analysis was conducted to trace EAM in the policy documents, both explicitly by closely scrutinizing the text and through connotations (combination of search words). The ten interviews conducted in spring/summer 2016 were semi-structured with questions following a guideline but still allowing flexibility depending on the situation and background of the interviewees (Bryman 2002). The experts were selected due to their involvement in development or implementation in the four policy areas. ${ }^{1}$ (Julien 2008; Berg 1998; Creswell 2014; Bryman 2002; Esaiasson et al. 2003) The interview material was collected and used to obtain more information, answer open questions and strengthen the other sources of information through triangulation and thus enhance their credibility (Julien 2008).

The article is structured as follows: In section 2 the EAM as the guiding principle of marine governance is presented and five criteria for assessing EAM are identified, followed by an analysis of the emergence of EAM in the four selected policy areas (section 3). Section 4 discusses how institutional interplay affects the spread of EAM and its implementation in the BSR. Finally, the results are presented in section 5.

\section{The Ecosystem Approach to Management (EAM)}

The fundamentals of ecosystem management can be traced back to the 1960s and Aldo Leopold's conservation ethics (Szaro, Sexton and Malone 1998). The discourse considering elements of ecosystem management has thus been addressed since the late 1970s and the 1980s (Grumbine 1994). The ecosystem approach to management is described as a critical shift in natural resource management. According to Maltby "we should regard the ecosystem approach as a holistic methodology or "process" to better integrate the biodiversity agenda" (Maltby 2000 p. 214). Ecosystem management can be described as a sustainable long-term management plan for socio-ecological systems which is placebased in the sense that it covers a specific area or region (Söderström, Kern, Boström and Gilek 2016).

\footnotetext{
${ }^{1}$ The snowball effect was used, meaning that some key informants were located who then recommended additional interviewees. Nine interviews were conducted by telephone or video link (Skype), and one interview was face-to face. All the interviews were recorded and fully transcribed. The interview material was analysed through content analysis, i.e. coded by themes to make it manageable.
} 
Historical failures in resource management prompted the development of new approaches; acknowledging the underestimated value of ecosystem services, sectoral boundaries, the mismatch of scales (Hammer 2015), weak stakeholder participation, unfair distribution of benefits and ambiguous connections between nature and culture as the major deficiencies (Maltby 2000). From this perspective ecosystem management can be seen as part of a sustainable development agenda. "To use a banking analogy, traditional approaches have been living off nature's capital, whereas EM is an attempt to live off nature's interest" (Grumbine 1997 p. 42).

The relevance of the ecosystem approach has grown steadily since it was emphasized at the Rio Earth Summit in 1992. Even though it is not mentioned explicitly in the original convention from 1992, the ecosystem approach is now considered to be the guiding principle of the Convention on Biological Diversity (CBD). At the fourth Conference of the Parties to the CBD (COP 4) in Bratislava (Slovakia) in 1998 it was defined as a holistic approach "that integrates the conservation and sustainable use of biological diversity, taking account of social and cultural and economic considerations" (COP IV Decision IV/1 1998 p. 103).

There is, however, a difference between the ecosystem approach and ecosystem management, even though the concepts are closely related. Maltby (2000) argues that the differences between the concepts are essential. While ecosystem management is judged in human terms and may change over time, the ecosystem approach comprises both a vision and a working plan to get there (Maltby 2000). During COP 4 of the CBD it was acknowledged that various concepts of EAM exist: "[...] the ecosystem approach has been addressed as a guiding principle, although the terminology used has varied, including: 'ecosystem approach', 'ecosystem process-oriented approach', 'ecosystem management approach' and 'ecosystem-based approach'” (COP IV Decision IV/1 1998 p. 56). Consequently, recent literature refers not only to ecosystem management and the ecosystem approach, but also to terms such as ecosystem-based management (Soma, van Tatenhove, and van Leeuwen 2015; Arkema, Abramson, and Dewsbury 2006), ecosystem-based approaches (Browman et al. 2004), ecosystem management approach (Hammer 2015) and adaptive ecosystem approach (Bunch 2003).

\section{Five Fundamental Criteria}

Although the labels differ, several core principles that are shared by most can be identified (Arkema, Abramson, and Dewsbury 2006). At COP 5 of the CBD in Nairobi (Kenya) in 2000 the ecosystem approach was defined as: "[...] a strategy for the integrated management of land, water and living resources that promotes conservation and sustainable use in an equitable way" (COP V Decision VI6 2000). It is guided through the interlinked twelve Malawi principles ${ }^{2}$ (COP V Decision VI6 2000), which

\footnotetext{
2 (1) Management objectives are a matter of societal choice; (2) management should be decentralized to the lowest appropriate level; (3) ecosystem managers should consider the effects of their activities on adjacent and other ecosystems; (4) recognizing potential gains from management there is a need to understand the ecosystem in an
} 
were developed during a CDB workshop in Lilongwe, Malawi, in 1998. Therefore, in this article the term Ecosystem Approach to Management (EAM) is used, which is defined by five criteria drawn from the twelve Malawi Principles, a literature review and existing practices of ecosystem management. EAM can be characterised by: (i) a holistic approach with human inclusion, (ii) scale dependency and integration, (iii) sound science, (iv) participation and (v) adaptive management and ecosystem services.

\section{(i) Holistic approach with human inclusion}

The most significant feature of EAM is the understanding of humans as part of the ecosystem, where human activities are seen as an integral part of ecosystem processes and thus of the management of natural resources (Pavlikakis and Tsihrintzis 2000; Szaro, Sexton, and Malone 1998; Naturvårdsverket 2008; McLeod and Leslie 2009; Endter-Wada et al. 1998; Grumbine 1994; Arkema, Abramson, and Dewsbury 2006; Hammer 2015; Curtin and Prellezo 2010). The anthropogenic approach requires the integration of ecological, social and economic aspects of management, acknowledging the centrality of socio-ecological systems and the need to integrate natural and social sciences (Engler 2015).

\section{(ii) Scale dependency and integration}

Finding the proper scale of management is essential, because the boundaries of ecosystems are difficult to recognize (Brussard, Reed, and Tracy 1998; Rosenberg and Sandifer 2009; Grumbine 1994; Curtin and Prellezo 2010). Both spatial and temporal scales are relevant here. EAM should comprise long-term management strategies, acknowledging that the results may be visible only in the long run (Naturvårdsverket 2008; Engler 2015). Taking spatial scales into account means, firstly, opting for the most appropriate ecological scale and determining the natural boundaries of ecosystems, although they may differ from political and administrative borders. This may require horizontal integration and cooperation across administrative and even national borders (Naturvårdsverket 2008; Endter-Wada et al. 1998; Grumbine 1994). Second, vertical cross-sectoral integration and coordination is needed, which may require administrative reorganisations (Wenzel 2016) at different levels.

\section{(iii) Sound science}

EAM should rely on sound science, including knowledge of complex ecosystem processes (Wang 2004; Curtin and Prellezo 2010). Ecosystem management already requires scientific data during decision-

economic context, considering e.g. mitigating market distortions, aligning incentives to promote sustainable use, and internalizing costs and benefits; (5) a key feature of the ecosystem approach includes conservation of ecosystem structure and functioning; (6) ecosystems must be managed within the limits to their functioning; (7) the ecosystem approach should be undertaken at the appropriate scale; (8) recognizing the varying temporal scales and lag effects which characterize ecosystem processes, objectives for ecosystem management should be set for the long term; (9) management must recognize that change is inevitable; (10) the ecosystem approach should seek the appropriate balance between conservation and use of biodiversity; (11) the ecosystem approach should consider all forms of relevant information, including scientific and indigenous and local knowledge, innovations and practices; and (12) the ecosystem approach should involve all relevant sectors of society and scientific disciplines 
making (Parr et al. 2003; Grumbine 1994). Data collection and monitoring must be solid and robust, and scientific evidence should be transparent and reliable (Engler 2015).

\section{(iv) Participation}

Inclusion of the knowledge and experiences of stakeholders and the public is also required (Naturvårdsverket 2008; Endter-Wada et al. 1998; Keough and Blahna 2006). Since stakeholder and citizen involvement is an integral part of ecosystem management (Söderström, Kern, Boström and Gilek 2016), various forms of cooperation (including public-private partnerships) have been discussed and tested. Participation may focus on individual actors, multi-actor processes (Olsson, Folke, and Berkes 2004) and multi-stakeholder partnerships (Bäckstrand 2006). This may, for example, encompass the management of land areas by local user groups (Colding, Lundberg, and Folke 2006) and affect the integration of land-based and marine spatial planning.

\section{(v) Adaptive management and ecosystem services}

EAM also requires the sustainable use of ecosystems in order to preserve ecosystem functions and the capability to provide these services in the future (Brussard, Reed, and Tracy 1998). Ecosystem services can be described as "biological, physical, and chemical processes that occur in natural or semi-natural ecosystems and maintain the habitability of the planet” (Brussard, Reed, and Tracy 1998 p. 10). Managers must be aware of the changing nature of ecosystems and thus adapt their behaviour accordingly (Naturvårdsverket 2008; Grumbine 1994; Bunch, McCarthy, and Waltner-Toews 2008). Adaptive management takes the uncertainties and complexities of natural systems into account and emphasizes the importance of flexibility and learning (Bunch 2003; Bunch, McCarthy, and WaltnerToews 2008; Olsson, Folke, and Berkes 2004). Endter-Wada et al (1998) regard adaptive management "not only as a scientific process by which we respond to ecological and social change, but also as a scientific process through which we reflect upon our processes of response" (Endter-Wada et al. 1998 p. 899). Since there will never be full information on all factors affecting ecosystems, the precautionary principle should be part of adaptive management (Curtin and Prellezo 2010).

\section{The Ecosystem Approach to Management in the Baltic Sea Region}

Based on these five criteria, this section traces and compares the EAM in the four most relevant marine policies in the BSR (see Table 1 below).

\subsection{EAM in the Baltic Sea Action Plan, Water Framework Directive, Marine Strategy Directive and Maritime Spatial Planning Directive}

\section{Baltic Sea Action Plan (BSAP)}

HELCOM's Baltic Sea Action Plan (BSAP), adopted in 2007, is an extensive document aiming for improvements in the Baltic Sea environment. The document is divided into the actual Action Plan, 
recommendations with detailed strategies and goals and a section on other documents to be adopted on the basis of the BSAP. ${ }^{3}$ The Action Plan is divided into sections covering eutrophication, hazardous substances, biodiversity and maritime activities. As already stated in its preamble, the BSAP is a plan for implementing EAM in the BSR: "RECALLING the 2003 Declaration of the First Joint Ministerial Meeting of the Helsinki and OSPAR Commissions to apply and further develop the measures necessary to implement an ecosystem approach to the management of human activities; ACKNOWLEDGING that the ecosystem approach is based on an integrated management of all human activities impacting on the marine environment and, based on best available scientific knowledge about the ecosystem and its dynamics, identifies and leads to actions improving the health of the marine ecosystem thus supporting sustainable use of ecosystem goods and services" (BSAP 2007 p.3). The holistic vision of joint management of various environmental problems is emphasized, alongside the importance of cooperation with already existing institutions, instruments and policies. Sound science and reliable data are stressed in the section on eutrophication in particular, but neither participation nor adaptive management or ecosystem services are given more than modest attention (BSAP 2007).

\section{Water Framework Directive (WFD)}

The Water Framework Directive (WFD) (Directive 2000/60/EC), which established a framework for action in the field of water policy, was adopted in 2000, annulling a number of older directives. The term 'ecosystem approach to management' (or similar) is not used explicitly, but some of the core characteristics of EAM can be found, for example human inclusion in river basin management and human impact on water resources, thus accounting humans as part of the ecosystem and indirectly referring to an holistic approach. Furthermore, the WFD has a strong focus on cross-sectoral and crossborder integration. The directive introduces a new type of management in river basins based on ecological rather than political and administrative borders. Integrative approaches are highlighted ${ }^{4}$ and cooperation between EU and non-EU member states is promoted. It explicitly states that the WFD should contribute to fulfilling regulations set by existing institutions such as the Helsinki Convention. Scientific knowledge and monitoring is discussed, although not in detail, while participation is only mentioned briefly and adaptive management is not mentioned at all (WFD 2000).

\section{Marine Strategy Framework Directive (MSFD)}

Although the process of developing a framework for marine environmental policy in the EU started in the early 2000s, the Marine Strategy Framework Directive (MSFD) (DIRECTIVE 2008/56/EC) did not

\footnotetext{
${ }^{3}$ This includes, for example, indicators and targets for reaching the ecological objectives in each environmental sector (for example for phosphorus and nitrogen reduction in agriculture), a roadmap for dealing with alien invasive species, a joint statement on emissions for the International Maritime Organization (IMO) and an Action Plan on offshore platforms.

${ }^{4}$ Integration with energy, transport, agriculture, fisheries, regional policy and tourism.
} 
come into force until 2008. It has since become a vital component of EU marine environmental governance regarding regulatory measures (Long 2011). In contrast to the WFD, which is limited to inland waters, the MSFD covers all marine waters. It aims to attain 'good environmental status' by 2020 . EAM is explicitly mentioned (as an ecosystem-based approach) as a means of attaining the goals of the MSFD (MSFD 2008, recital 8, recital 44, Article 1(3)). The holistic approach is indirectly discussed by emphasising the need to address all human-induced impacts on the marine environment. As well as cross-border and cross-sectoral integration, the need for and reliance on scientific knowledge, research and monitoring are acknowledged. Coordination with other EU policies is stressed, and cooperation with non-EU countries is encouraged. Like the WFD, the MSFD has to support other institutions such as regional seas conventions. Public participation and the involvement of stakeholders are occasionally mentioned, but are not elaborated further, while adaptive management and ecosystem services are discussed explicitly (MSFD 2008).

\section{Maritime Spatial Planning Directive (MSPD)}

The Marine Strategy Planning Directive (DIRECTIVE 2014/89/EU) from 2014 establishes a framework for maritime spatial planning. The main purpose of this directive is to manage marine resources in a sustainable way through integrated spatial planning, encourage multi-purpose uses and manage conflicts (MSPD 2014, recital 19). The directive refers to other policies and their timelines. EAM (referred to as an ecosystem-based approach) is emphasised several times. The holistic and cross-sectoral nature of the directive is highlighted: "The application of an ecosystem-based approach will contribute to promoting the sustainable development and growth of the maritime and coastal economies and the sustainable use of marine and coastal resources" (MSPD 2014, recital 3). Like the MSFD, the MSPD aims to attain good environmental status and develop an integrated management approach for the use of marine and coastal resources. Overall, this directive explicitly embraces the core elements of EAM. The holistic approach is evident in that the sea is to be considered as a whole and integrated management is required. Cross-sectoral integration is highlighted with an emphasis on land-sea interactions and cross-border cooperation. Moreover, the directive stresses the need for sound science, reliable data and utilisation of already existing knowledge from different sources. Maritime Spatial Planning is described as a crosscutting instrument for integrative measures based on the involvement of both public authorities and stakeholders. Adaptive management and the importance of ecosystem services is discussed in brief (MSPD 2014).

\subsection{Comparison between the policy areas}

Although the 'ecosystem approach' or 'ecosystem-based approach' is explicitly mentioned in all policies except for the WFD, the four policies differ considerably when compared across all five criteria (see table 1 below). Some criteria are more prominent than others: the need for a holistic approach and 
human inclusion (criterion 1) is explicitly addressed only in the BSAP and the MSPD, while it is indirectly or moderately stated in the MSFD and the WFD. Scale dependency and integration (criterion 2) are explicitly noted in all four documents. The BSAP in particular strongly emphasises coordination with other institutions. This refers not only to EU directives, IMO regulations and international conventions but also to other institutions such as VASAB (Vision and Strategies Around the Baltic Sea), Baltic 21 and the INTERREG Programme for the Baltic Sea. The need to strengthen sub-regional cooperation and encourage bi- and multilateral agreements as well as joint operations (e.g. aerial surveillance) is highlighted in Recommendation 28E/12 (BSAP 2007 p.65). The WFD in particular requires ecological boundaries to be respected by adopting river basin management plans (RBMPs). If a river basin crosses national borders, a joint plan needs to be developed if the neighbouring country is an EU member state, while coordination is encouraged if the neighbouring country is not an EU member state (WFD 2000, recital 35, Article 3, Article 13). Both the WFD and the MSFD emphasise the need for cooperation, coordination and support of already existing institutions. In addition, the MSPD stresses cross-sectoral integration and international cooperation. The need for sound science and knowledge (criterion 3) is explicitly emphasised in all documents except the WFD, which at least refers to it as an important precondition. Since the MSPD is the only document to take an active stand in promoting participation (criterion 4), this feature is the least developed among the five criteria. The BSAP contains a section on 'awareness raising and capacity building' (BSAP 2007 p. 31), while the WFD and the MSFD focus only briefly on the dissemination of information and public participation. Adaptive management and ecosystem services (criterion 5) also hold a less prominent position because the MSFD only refers to it explicitly. In the MSPD it is mentioned briefly and in the BSAP only in the preamble and the section on eutrophication, while it is totally absent in the WFD.

Since the EAM is least prominent in the oldest document, the WFD (2000), and most pronounced in the most recent document, the MSPD (2014), with the BSAP and the MSFD somewhere in between (Table 1), it can be assumed that, first, the impact of the EAM on the four documents increased over time and that, second, the four documents considerably influenced each other.

Although EAM has become a core element of EU marine policy and the BSAP, implementation problems occur due to a lack of cross-sectoral integration and cross-boundary solutions (Curtin and Prellezo 2010; Hegland, Raakjær, and van Tatenhove 2015; Boström, Grönholm, and Hassler 2016). Furthermore, the BSAP is implemented through national implementation plans (NIPs) which still lack consistency (Gilek et al. 2013). Regarding the implementation of EAM within the MSFD, Ounanian et al (2012) identify problems with ecological boundaries, policy and management coordination and conflicts of users and values (Ounanian et al. 2012). This is caused, for example, by the mismatch between environmental quality assessments required by the WFD and MSFD because the definition of ecological/environmental status differs between the two directives (Doneliene 2016; interviews 7, 8). Moreover, the balance between the social, economic and ecological pillars of sustainability has shifted. 
While the WFD and MSFD emphasise the ecological dimension, the EU's Blue Growth Strategy, of which MSPD forms part, focuses primarily on economic development (Soma, van Tatenhove, and van Leeuwen 2015; interview 10).

As institutional interplay between the EU and HELCOM influences not only the prominence of EAM in agenda-setting and decision-making in both institutions but also its implementation at the national and subnational levels, the next section focuses on the different forms of institutional interplay in the BSR.

Table 1, core characteristics of EAM in major European policy documents

\begin{tabular}{lllll}
\hline & HELCOM & \multicolumn{2}{l}{ European Union } & \\
Characteristics & BSAP & WFD & MSFD & MSPD \\
\hline Hol. approach/human incl. & +++ & + & ++ & +++ \\
Scale-dependency/integration & +++ & +++ & +++ & +++ \\
Sound science & +++ & + & +++ & +++ \\
Participation & ++ & ++ & ++ & +++ \\
Adpt. Mang/eco serv. & ++ & - & +++ & ++ \\
& & & & \\
\hline
\end{tabular}

- = Not mentioned at all, + = Referred to indirectly,

$++=$ Mentioned just once or twice, $+H=$ Explicitly stated and discussed

\section{Institutional Interplay and the Ecosystem Approach to Management in the Baltic Sea Region}

Though EAM has been acknowledged as the guiding principle of marine governance, its impact on the management of ecosystems in the Baltic Sea region depends on the dissemination of this idea, its integration into policy-making and the implementation of such policies. Based on the findings above, this section examines the application and implementation of the EAM in the BSR in more detail. It aims to find an explanation for the identified differences between the four policy areas with regard to EAM. Starting from the assumption that institutional interplay and its specific spatio-temporal configurations affect the spread of EAM and its implementation, this section concentrates on institutional interplay in agenda-setting, decision-making and implementation from the global to the local level.

The debate on institutional interplay provides a promising approach to analysing the interdependent debates on EAM in the BSR. Institutional interplay concentrates on the causal relationship between two or more institutions with at least one of these institutions exerting influence on the other(s) (van Leeuwen and Kern. 2013). These interactions range from unilateral influences of one institution on another institution to complex multilateral interactions, with several institutions influencing each other (Selin 
and VanDeveer 2003). Interplay between institutions may lead to positive feedback (synergies) as well as negative feedback (disruptions) (cf. Young 2002; Gehring and Oberthür 2006).

\subsection{Scope and scale of institutional interplay in the Baltic Sea region}

Overlap between (regional) institutions affects the scope and scale of institutional interplay. While scope refers to the horizontal dynamics between institutions, scale is relevant to the vertical dynamics between institutions from the global to the local level (cf. van Leeuwen and Kern. 2013). Moreover, spatial as well as temporal scales are relevant to analysing the spread of EAM in the region. Institutional interplay between the EU and HELCOM may lead to synergies of marine governance in the BSR, and norms regulating the marine environment of the Baltic Sea may converge around the EAM and even influence development in other European regional sea areas such as the North Sea or the Mediterranean Sea.

In contrast to HELCOM, which (today) is made up of eight EU member states and Russia as the only non-member state, the EU currently encompasses 20 additional member states outside the BSR (Figure 1). Depending on this group of eight EU member states (and the European Commission) $)^{5}$ and their ability to influence Russia (in the case of HELCOM) and the 20 member states outside the BSR (in the case of the EU), HELCOM recommendations and EU legislation on marine governance have converged over time. The EU's Eastern Enlargement considerably changed the situation in the BSR, since there were only four EU member states in the region before 2004, while Poland and the three Baltic states were only candidate countries. Such differing spatio-temporal configurations may be relevant for the spread and implementation of the EAM, because prior to 2004 the most important discussions and decisions in Brussels on water and marine policy (e.g. on the WFD) were restricted to the then four EU member states in the region (Finland, Sweden, Denmark and Germany). Since the EU's Eastern Enlargement in 2004, all the coastal states in the BSR, except Russia, have been EU member states. It seems that this new spatio-temporal configuration strengthened the influence of the EU in the BSR and simultaneously the influence of voices from the BSR in Brussels.

While the EU has no formal control over HELCOM recommendations and vice versa, initiatives launched by one institution can have far-reaching consequences for the other institution, not only because of overlapping membership but also because decision-making rules and compliance systems differ. In contrast to HELCOM recommendations, EU legislation is binding for all member states and compliance systems are more stringent. This means that interplay between HELCOM and the EU is influenced by dynamics caused by the differing rules for the two institutions. This may even lead to strategies developed by one institution with the aim of affecting the other institution.

\footnotetext{
${ }^{5}$ The EU itself is also a sign atory of the (revised) Helsinki Convention.
} 


\section{EU HELCOM}

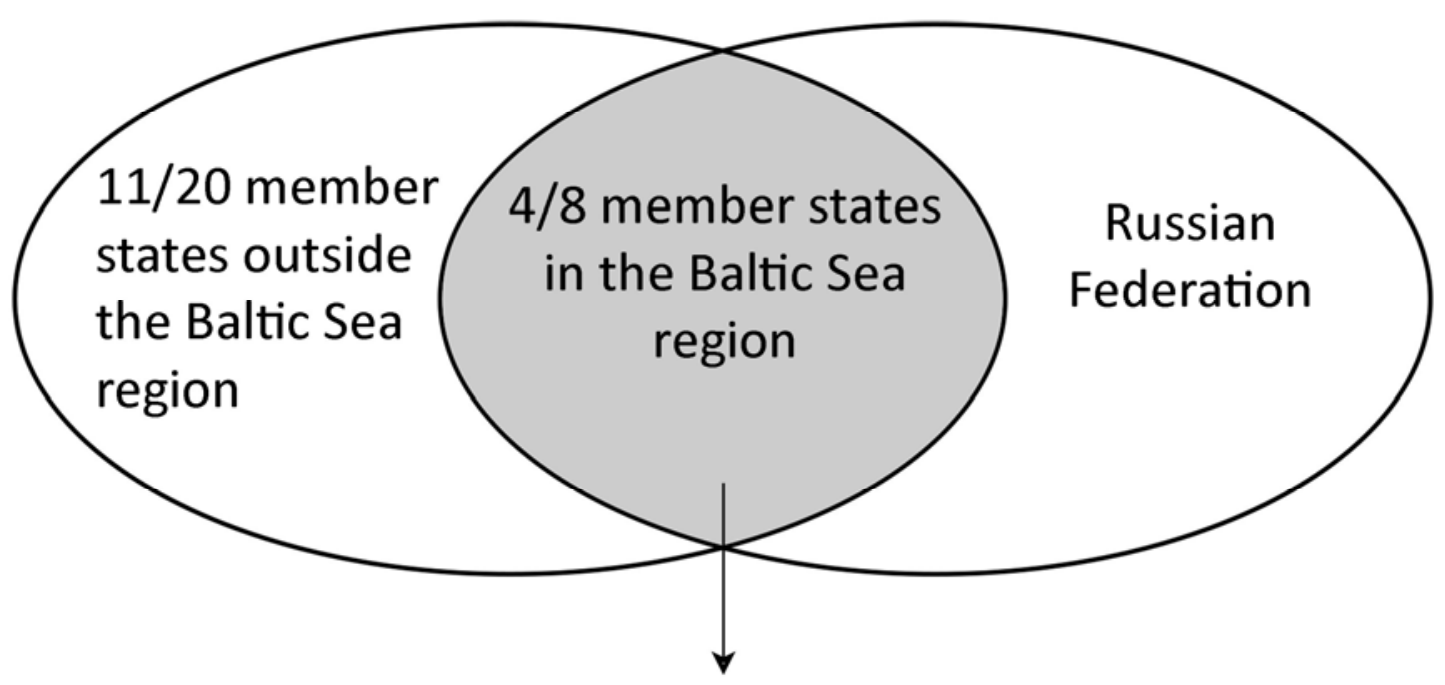

Overlapping membership

Horizontal interplay between HELCOM and the EU is complemented by vertical interplay between these institutions on the one hand and national and subnational institutions on the other. This is particularly relevant to the implementation phase of EAM, because both HELCOM recommendations and EU directives need to be implemented at national and subnational levels. Although there are differences between the four policy areas analysed in this article (BSAP, WFD, MSFD, MSPD) when it comes to implementation, they all require national (and even subnational) implementation plans and strategies for EAM and, if necessary, new transnational arrangements to manage transnational ecosystems.

\subsection{Three causal mechanisms for institutional interplay: cognition, commitment and compliance}

Research on institutional interplay suggests various typologies for classifying the different patterns of interplay between two institutions (Gehring and Oberthür 2006; Selin and VanDeveer 2003). While Stokke (2001) examines ideational, normative and utilitarian interaction, Gehring and Oberthür (2006; 2009) focus on causal mechanisms and propose studying (i) cognitive interaction, (ii) interaction through commitments and (iii) behavioural interaction. Based on this literature, this article starts from the assumption that institutional interplay between the EU and HELCOM and its impact on EAM application and implementation in the BSR are driven by three causal mechanisms - cognition, commitment and compliance (see van Leeuwen and Kern. 2013). 


\section{Interplay through cognition}

Cognitive interplay is characterised by the spread of ideas, knowledge and new concepts such as the EAM (Daniel and Cox 2011; Bulmer and others 2007; Kern 2000; Stokke 2001; Gehring and Oberthür 2011). Although cognitive interplay may influence the decision-making and implementation phase of policies, this type of interplay occurs primarily in the agenda-setting phase when policies are developed. New approaches such as the EAM may travel from one institution to another. Due to different forms of inter-organisational learning (Alcock 2011; Stokke 2001), new approaches may change during the process, i.e. cognitive interplay can extend from inspiration to emulation and even copying (Kern 2000; Rose, 2005). Although institutional interplay can be a unidirectional process with ideas flowing only from one institution to another, more complex forms of cognitive interplay may lead to joint learning, positive feedback and the emergence of converging policy discourses in different institutions.

In the WFD, which already came into force before Poland, Lithuania, Latvia and Estonia joined the EU, several of the EAM elements are already present, although EAM is not mentioned explicitly. It is innovative, however, with respect to the use of ecological boundaries instead of administrative borders. This difference between the WFD and previous strategies is fully in line with the essence of EAM. The directive is intended to help member states to fulfil their obligations with respect to international agreements, including regional sea conventions (WFD 2000:21 p 3). As the WFD does not refer to EAM explicitly, the directive can be seen as a transitional initiative half-way between traditional management approaches and EAM.

In contrast to the WFD, the MSFD contains a clear statement pointing to EAM, and the directive itself has become something of a hub for EAM since several other EU documents refer to its EAM definition. It can therefore be assumed that cognitive interplay played a role here and the three EU directives influenced each other in a unilateral way, starting with the WFD, which influenced the MSFD, which in turn influenced the MSPD. This is most obvious for the MSFD because it refers directly to the MSFD. Although cognitive interplay exists between the three EU policy initiatives, it is even more evident between the EU and HELCOM, especially between the MSFD and the BSAP (Backer et al. 2010; van Leeuwen, van Hoof, and van Tatenhove 2012; van Tatenhove et al. 2014; Wenzel 2011; Karlsson, Gilek, and Lundberg 2016). Before the MSFD was developed the EAM was not yet established as the guiding principle of EU marine policy. This was confirmed by a member of the Head of Delegations (HELCOM): “MSFD was new, they didn't have anything other than WFD to build on. So that was the base and structure. But other than that it was nothing. Totally unregulated. So it was the regional conventions that was the option" (interview 3). When developing the MSFD, it was a deliberate decision to use the already existing knowledge acquired by HELCOM and OSPAR. Thus, cognitive interplay between the EU and HELCOM is most evident in the development phase of the MSFD since it was influenced by the BSAP, which was developed in the BSR almost simultaneously and vice versa. This 
is explained by an expert from the Government Offices of Sweden who worked with the development and implementation of the MSFD: "Our idea with the BSAP was that it was the programme of measures for the MSFD. That was how we saw it when we started working with it." (interview 4).

It can be concluded that (i) cognitive interplay regarding the EAM started with global initiatives, in particular in the context of the Convention on Biological Diversity; (ii) EAM was soon adopted by the EU and HELCOM in a somewhat unilateral process; (iii) this led to a dynamic interdependent relationship and synergies between the EU and HELCOM (i.e. between the MSFD and the BSAP), in particular after the EU's Eastern Enlargement; (iv) this process was accompanied by a far more linear and unilateral form of cognitive interplay between the different EU policy initiatives, from the WFD to the MSFD and finally the MSPD (Figure 2).

Figure 2, cognitive interplay between HELCOM and the EU

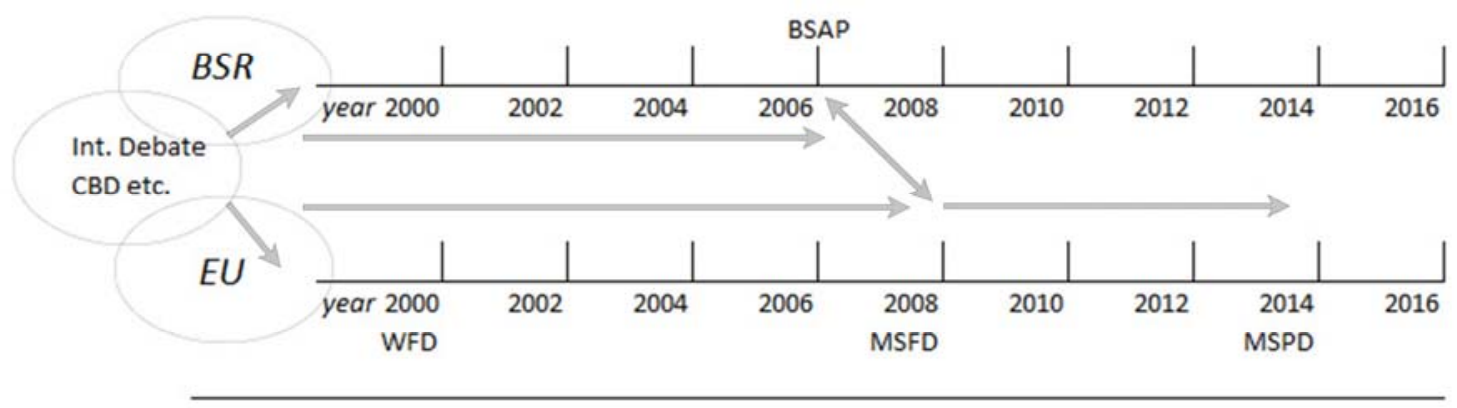

\section{Interplay through commitment}

In contrast to cognitive interplay, interplay through commitment is most important for decision-making. In overlapping institutions (such as HELCOM and the EU) commitments adopted by one institution automatically affect decision-making within the other institution (Gehring and Oberthür 2011; Leeuwen and Kern. 2013). This is essential for the institutional interplay between HELCOM and the EU, because decision-making procedures differ considerably. While HELCOM recommendations are non-binding, EU legislation is binding and needs to be transposed into national law. If actors present in both decisionmaking arenas change their preferences and positions with regard to EAM, they may become policy entrepreneurs (Kingdon 2014). Based on similar discourses on EAM which frame the problem definition, policy entrepreneurs in overlapping institutions are in a privileged position because they can influence both institutions simultaneously and can switch between policy arenas to pursue their interests. They may even push for the adoption of new approaches, such as the EAM, in both institutions simultaneously. 
Differing decision-making rules between the EU and HELCOM created incentives for such strategies. As discussed in the previous section, the interplay between the BSAP and the MSFD is significant for the adoption of EAM as a guiding principle of marine governance in the BSR. The pattern in the BSR and in Brussels with the EU and its member states, on the one hand, and HELCOM, on the other, was described by an expert as two differing systems. From this perspective the MSFD can be regarded as the link between the two systems (interview 8). Several experts with experience from both EU and HELCOM confirmed that this setting can lead to diverging opinions and positions between representatives from member states within and outside the BSR (interviews 3,6). They claim that some participants at EU meetings do not even possess adequate knowledge and show no interest in Baltic Sea issues due to the geographical distance between their country and the BSR (interview 7).

Several interviewees described the negotiations within HELCOM as more open due to the fact that the end product is not legally binding. In contrast, EU negotiations seem to follow stricter rules, and every word is spoken with caution (interviews 3, 6, 8). However, according to these experts, the MSFD (and its position on EAM) has gradually taken over the BSAP (interviews 2, 3, 7, 8, 10). This development has made HELCOM negotiations more challenging, because there is now a fear that HELCOM recommendations could become legally binding requirements under the MSFD. A German expert noted: "The requirement to use existing regional cooperation structures for the regional coordination of EU countries' MSFD implementation is making international cooperation slightly more difficult, because countries carefully consider potential implications of international cooperation in relation to the legal implementation of the MSFD.” (Interview 8).

Interplay through commitment has led to synergies and convergence in the BSR because this form of interplay strengthened HELCOM's non-binding recommendations by elevating them to the EU level and turning them into binding EU law in form of the MSFD. Thus, it comes as no surprise that EAM implementation strategies have converged between HELCOM (i.e. the BSAP) and the EU (i.e. the MSFD). The downside of this mechanism are the implications for HELCOM decision-making, because it becomes harder to find a consensus within HELCOM due to the "shadow of binding EU decisions". HELCOM may thus lose momentum and develop from an independent institution with its own mission into an instrument for implementing EU policies.

\section{Interplay through compliance}

Interplay through compliance is a causal mechanism which has effects on the implementation phase. The implementation of policies in one institution may lead to changes in another institution (Gehring and Oberthür 2006; Gehring and Oberthür 2009). Interplay through compliance does not affect the agenda-setting and decision-making process directly but rather determines the performance of an institution. In the case of overlapping institutions, this may cause synergies if compliance systems converge, as well as disruptions if they diverge. If decision-making and compliance systems differ 
considerably between overlapping institutions, as is the case between HELCOM and the EU, convergence of marine policies in the BSR can be reached by changing HELCOM's compliance system and adapting it to EU rules (Backer et al. 2010; Söderström, Kern and Hassler 2015; van Leeuwen, van Hoof and van Tatenhove 2012).

Interplay through commitment and interplay through compliance differ with regard to their spatiotemporal configurations because marine policies, based on EAM as their core principle, need to be implemented at national and subnational levels. As these agencies are confronted with different compliance systems, they may have incentives to harmonise them in line with the requirements of EAM. This development is supported by the EU Strategy for the Baltic Sea Region because it refers directly to the implementation of HELCOM Recommendations (Gänzle and Kern 2016).

As the previous section has shown, the BSAP and the three EU directives are all based on the EAM as their guiding principle, but to differing degrees. However, all countries are required to produce National Implementation Plans for the BSAP and for EU directives, which is most often accomplished within the same implementing agency, meaning that EAM implementation leads to new institutional complexes at the national and subnational levels. Unilateral forms of institutional interplay are replaced by complex forms of interplay among marine policies. This is supported by the arguments of a Swedish interviewee who pointed out that, at least in Sweden, the targets in the BSAP have become part of the implementation plans for the WFD (interview 4) and the MSFD and by the position of another expert who emphasised the need to avoid conducting the same assessments twice (interviews 8,10 ). This may require a reorganisation of national (and even subnational) agencies which are in charge of implementing HELCOM recommendations and EU directives (Wenzel 2016, 159-167).

It can be concluded that assessments required by the BSAP are made in such a way that they can also be used for assessments required by binding EU directives such as the MSFD, while actions which cannot be used directly for the implementation of EU directives might be neglected. This means that interplay through compliance seems to have similar effects to interplay through commitment because with respect to the implementation of the EAM in the BSAP and the EU directives the BSAP compliance system is increasingly dominated by the EU compliance system. This has repercussions for HELCOM, because it leads to increasing resistance by Russia to accepting this changing situation. ${ }^{6}$

\section{Conclusions}

The ecosystem approach to management marks a fundamental shift from traditional management of natural resources towards a holistic and integrative approach. Although experts and scientists have not yet agreed on a generally accepted definition, the concept has spread to marine environmental governance. EAM was developed at the global level, in particular around the debates on the Convention

\footnotetext{
${ }^{6}$ Delegates from Russia have, for example, started to refrain from attending meetings of HELCOM's working group on implementation (interview 10).
} 
on Biological Diversity, and was soon after taken up by both the EU and HELCOM. EAM has thus become a vital part of HELCOM's Baltic Sea Action Plan and the EU's marine policy.

The core elements of EAM are more or less present in all four policy areas. In the BSR, marine governance has been expanded and has become highly institutionalised. Due to general debates on EAM and changing spatio-temporal configurations (for example through the Eastern Enlargement of the EU), a trend towards increasing impact of EAM can be identified, starting with the WFD from 2000 to the MSPD from 2014. The WFD can be regarded as a transitional policy halfway between the old management paradigm and a new holistic approach. Since the MSFD explicitly defines the EAM as a target, vision and strategy, the directive has become a hub of marine environmental governance in the BSR with regard to EAM. Thus, it comes as no surprise that the most recent directive on marine issues, the MSPD, explicitly refers to the MSFD. The MSPD is designed as a tool for implementing the EAM, but has not yet developed its full potential because it was not adopted until 2014. Although EAM has become very prominent for both EU marine policy and HELCOM recommendations, severe implementation deficits, mainly due to a lack of sectoral integration, still exist.

Agenda-setting, decision-making and implementation of the EAM in marine policy in the BSR have been influenced by institutional interplay. With regard to cognitive interplay, which affects agendasetting, the study finds unilateral links between the three EU directives as well as more complex forms of interplay between HELCOM's BSAP and the EU's MSFD. This can be explained mainly by the specific spatio-temporal configurations, i.e. the fact that the two institutions developed almost simultaneously. Interplay through commitment is most relevant for decision-making. Differing rules for decision-making in the EU and HELCOM have led to synergies because non-binding HELCOM recommendations were elevated to the EU level and transformed into binding EU directives. Interplay through compliance affects the implementation phase and causes synergies because the EU has developed a far more stringent compliance system than HELCOM. In addition, the relationship between EU directives and HELCOM has been strengthened because both the BSAP and EU directives include provisions to coordinate implementation with other relevant institutions.

However, the interplay between the EU and HELCOM does not just cause synergies, it also has its downsides. Although both institutions support a deliberate move towards protecting marine resources based on EAM and utilise already existing knowledge, institutional interplay between HELCOM and the EU in marine policy has generated a relationship characterised by EU dominance. As HELCOM recommendations may be transformed into binding EU directives, HELCOM negotiations become more challenging due to this 'shadow of binding EU decisions'. The EU's MSFD seems to dominate HELCOM's BSAP, which functions more and more as a kind of EAM implementation plan. In essence, the EU formally utilises HELCOM as a regional facilitator for implementing EU directives in the BSR. As EU directives and BSAP recommendations must eventually be implemented at national and subnational levels, the coordination of national implementation plans (for implementing the BSAP, the 
WFD and the MSFD) has become necessary, most often accompanied by administrative reorganisations aiming for adequate EAM implementation. As well as implementation problems caused by differing quality assessments required by the WFD and the MSFD, the implementation of HELCOM's BSAP is adapted to and even restricted by the requirements of EU marine policy. It can be concluded that HELCOM's function as an agency with increasing responsibilities for the implementation of EU legislation limits its independence but not its importance for the BSR, since the inclusion of Russia is an essential prerequisite for cleaning up the Baltic Sea. 


\section{Bibliography}

Alcock, Frank. 2011. UNCLOS, Property Rights, and Effective Fisheries Management: The Dynamics of Vertical Interplay. In Managing Institutional Complexity. Regime Interplay and Global Environmental Change, edited by Sebastian Oberthür and O. S. Stokke, 255-283. Cambridge: MIT Press.

Arkema, Katie K., Sarah C. Abramson, and Bryan M. Dewsbury. 2006. Marine Ecosystem-Based Management: From Characterization to Implementation. Frontiers in Ecology and the Environment 4 (10): 525-532.

Backer, H., J. M. Leppänen, A. C. Brusendorff, K. Forsius, M. Stankiewicz, J. Mehtonen, M. Pyhälä, M. Laamanen, H. Paulomäki, and N. Vlasov. 2010. HELCOM Baltic Sea Action Plan-A Regional Programme of Measures for the Marine Environment Based on the Ecosystem Approach. Marine Pollution Bulletin 60 (5): 642-649.

Bäckstrand, K. 2006. Multi-stakeholder Partnerships for Sustainable Development: Rethinking Legitimacy, Accountability and Effectiveness. European Environment 16 (5): 290-306.

Berg, Bruce Lawrence. 1998. Qualitative Research Methods for the Social Sciences. 3rd ed. Vol. 3. United States of America: Allyn \& Bacon.

Boström, Magnus, Sam Grönholm, and Björn Hassler. 2016. The Ecosystem Approach to Management in Baltic Sea Governance: Towards Increased Reflexivity? In Environmental Governance of the Baltic Sea, 149-172: Springer.

Browman, Howard I., Philippe M. Cury, Ray Hilborn, Simon Jennings, Heike K. Lotze, Pamela M. Mace, Steven Murawski, Daniel Pauly, Michael Sissenwine, and Konstantinos I. Stergiou. 2004. Ecosystem-Based Management. Mar.Ecol.Prog.Ser. 274: 269-303.

Brussard, Peter F., J. Michael Reed, and C. Richard Tracy. 1998. Ecosystem Management: What is it really? Landscape and Urban Planning 40 (1): 9-20.

Bryman, Alan. 2002. Samhällsvetenskapliga Metoder. 1st ed. Trelleborg: Liber Ekonomi.

BSAP. 2007. HELCOM Baltic Sea Action Plan.

Bulmer, Simon, David Dolowitz, Peter Humphreys, and Stephen Padgett. 2007. Policy Transfer in European Union Governance: Regulating the Utilities Routledge.

Bunch, Martin. 2003. Soft Systems Methodology and the Ecosystem Approach: A System Study of the Cooum River and Environs in Chennai, India. Environmental Management 31 (2): 01820197.

Bunch, Martin, Dan McCarthy, and David Waltner-Toews. 2008. A Family of Origin for an Ecosystem Approach to Managing for Sustainability. The Ecosystem Approach: Complexity, Uncertainty, and Managing for Sustainability. New York: Columbia Univ Pr: 125-138.

Colding, Johan, Jakob Lundberg, and Carl Folke. 2006. Incorporating Green-Area User Groups in Urban Ecosystem Management. AMBIO: A Journal of the Human Environment 35 (5): 237-244. 
COP IV Decision IV/1. 1998. Unep/Cbd/Cop/4/27; Report of the Fourth Meeting of the Conference of the Parties to the Convention on Biological Diversity. Bratislava, 4-15 May 1998.

COP V Decision VI6. Fifth Meeting of the Conference of the Parties to the Convention on Biological Diversity Nairobi, Kenya 15 - 26 May 2000. Kenya.

Creswell, John W. 2014. Research Design: Qualitative, Quantitative, and Mixed Methods Approaches. Fourth Edition ed. Thousand Oaks, USA; London, UK; New Delhi, India; Singapore: Sage Publications.

Curtin, Richard and Raúl Prellezo. 2010. Understanding Marine Ecosystem Based Management: A Literature Review. Marine Policy 34 (5): 821-830.

Daniel, Béland and Robert H. Cox, eds. 2011. Ideas and Politics in Social Science Research. Oxford: Oxford University Press.

Doneliene, Margarita. 2016. Eutrophication Governance in the Baltic Sea Region: Institutional Interplay and the Problem of Fit, Dissertation, Freie Universität Berlin.

Endter-Wada, Joanna, Dale Blahna, Richard Krannich, and Mark Brunson. 1998. A Framework for Understanding Social Science Contributions to Ecosystem Management. Ecological Applications 8 (3): 891-904.

Engler, Cecilia. 2015. Beyond Rhetoric: Navigating the Conceptual Tangle Towards Effective Implementation of the Ecosystem Approach to Oceans Management. Environmental Reviews 23 (3): $288-320$.

Esaiasson, Peter, Michael Gilljam, Henrik Oscarsson, and Lena Wängnerud. 2003. Metodpraktikan: Konsten Att Studera Individ, Samhälle Och Marknad. Stockholm: Nordstedts Juridik $A B$.

Gehring, Thomas and Sebastian Oberthür. 2009. The Causal Mechanisms of Interaction between International Institutions. European Journal of International Relations 15 (1): 125-156.

Gehring, Thomas and Sebastian Oberthür. 2011. Institutional Interaction: Ten Years of Scholarly Development. Managing Institutional Complexity: Regime Interplay and Global Environmental Change, edited by Sebastian Oberthür andOlav Schram Stokke.

Gehring, Thomas and Sebastian Oberthür. 2006. Introduction. In Institutional Interaction in Global Environmental Governance: Synergy and Conflict among International and EU Policies, edited by Sebastian Oberthür and Thomas Gehring, 1-18. Cambridge, Massachusetts; London, England: MIT Press.

Gilek, Michael, Björn Hassler, Fanny Engkvist, and Kristine Kern. 2013. The HELCOM Baltic Sea Action Plan: Challenges of Implementing an Innovative Ecosystem Approach. Baltic Development Forum.

Gritsenko, Daria. 2013. The Russian Dimension of Baltic Maritime Governance. Journal of Baltic Studies 44 (4): 425-449.

Grumbine, R. Edward 1994. What is Ecosystem Management? Conservation Biology 8 (1): 27-38. 
Grumbine, R. Edward. 1997. Reflections on "What is Ecosystem Management?" Conservation Biology 11 (1): 41-47.

Gänzle, Stefan and Kristine Kern. 2016. The European Union Strategy for the Baltic Sea Region. In A 'Macro-Regional' Europe in the Making: Theoretical Approaches and Empirical Evidence, edited by Stefan Gänzle and Kristine Kern, 123-144. Hampshire and New York: Palgrave Macmillan.

Hammer, Monica. 2015. The Ecosystem Management Approach: Implications for Marine Governance. In Governing Europe's Marine Environment: Europeanization of Regional Seas Or Regionalization of EU Policies?, edited by Michael Gilek and Kristine Kern, 75-92. Surrey, England: Ashgate.

Hegland, Troels Jacob, Jesper Raakjær, and Jan van Tatenhove. 2015. Implementing EcosystemBased Marine Management as a Process of Regionalisation: Some Lessons from the Baltic Sea. Ocean \& Coastal Management 117: 14-22.

Julien, Heidi. 2008. Content Analysis. In The SAGE Encyclopedia of Qualitative Research Methods, edited by Lisa M. Given. Thousand Oaks: SAGE Publications Inc.

Karlsson, Mikael, Michael Gilek, and Cecilia Lundberg. 2016. Eutrophication and the Ecosystem Approach to Management: A Case Study of Baltic Sea Environmental Governance. In Environmental Governance of the Baltic Sea, 21-44: Springer.

Keough, Heather L. and Dale J. Blahna. 2006. Achieving Integrative, Collaborative Ecosystem Management. Conservation Biology 20 (5): 1373-1382.

Kern, K. 2000. Die Diffusion von Politikinnovationen: Umweltpolitische Innovationen im Mehrebenensystem der USA. Opladen: Leske \& Budrich

Kern, K. 2011. Governance for Sustainable Development in the Baltic Sea Region. Journal of Baltic Studies 42 (1): 21-35.

Kingdon, John W. 2014. Agendas, Alternatives and Public Policies. 2nd ed ed. Harlow, Essex: Pearson.

Long, Ronan. 2011. The Marine Strategy Framework Directive: A New European Approach to the Regulation of the Marine Environment, Marine Natural Resources and Marine Ecological Services. Journal of Energy \& Natural Resources Law 29 (1): 1-44.

Maltby, Edward. 2000. Ecosystem Approach: From Principle to Practice. Beijing

McLeod, Karen and Heather Leslie. 2009. Ecosystem-Based Management for the Oceans. Washington D.C.: Island Press.

MSFD. DIRECTIVE 2008/56/EC OF THE EUROPEAN PARLIAMENT AND OF THE COUNCIL of 17 June 2008 Establishing a Framework for Community Action in the Field of Marine Environmental Policy (Marine Strategy Framework Directive), (2008)

MSPD. 2014. DIRECTIVE 2014/89/EU OF THE EUROPEAN PARLIAMENT AND OF THE COUNCIL of 23 July 2014 Establishing a Framework for Maritime Spatial Planning. 
Naturvårdsverket. 2008. Ekosystemansatsen - En Väg Mot Bevarande Och Hållbart Nyttjande Av Naturresurser, Naturvårdsverket.

Olsson, Per, Carl Folke, and Fikret Berkes. 2004. Adaptive Co-management for Building Resilience in Social-ecological Systems. Environmental Management 34 (1): 75-90.

Ounanian, Kristen, Alyne Delaney, Jesper Raakjær, and Paulina Ramirez-Monsalve. 2012. On Unequal Footing: Stakeholder Perspectives on the Marine Strategy Framework Directive as a Mechanism of the Ecosystem-Based Approach to Marine Management. Marine Policy 36 (3): 658666.

Parr, Terry W., Andrew RJ Sier, RW Battarbee, Anson Mackay, and Jacquie Burgess. 2003. Detecting Environmental Change: Science and Society - perspectives on Long-Term Research and Monitoring in the 21st Century. Science of the Total Environment 310 (1): 1-8.

Pavlikakis, Georgios E. and Vassilios A. Tsihrintzis. 2000. Ecosystem Management: A Review of a New Concept and Methodology. Water Resources Management 14 (4): 257-283.

Rosenberg, Andrew A. and Paul A. Sandifer. 2009. What do Managers Need? Ecosystem-Based Management for the Oceans 13: 14-15.

Selin, Henrik and Stacy D. VanDeveer. 2003. Mapping Institutional Linkages in European Air Pollution Politics. Global Environmental Politics 3 (3): 14-46.

Soma, Katrine, Jan van Tatenhove, and Judith van Leeuwen. 2015. Marine Governance in a European Context: Regionalization, Integration and Cooperation for Ecosystem-Based Management. Ocean \& Coastal Management.

Stokke, Olav Schram. 2001. The Interplay of International Regimes: Putting Effectiveness Theory to Work. Oslo: Fridtjof Nansen Institute.

Szaro, Robert C., William T. Sexton, and Charles R. Malone. 1998. The Emergence of Ecosystem Management as a Tool for Meeting People's Needs and Sustaining Ecosystems. Landscape and Urban Planning 40 (1): 1-7.

Söderström, S., Kern, K., \& Hassler, B. (2015). Marine governance in the baltic sea: Current trends of europeanization and regionalization. In M. Gilek, \& K. Kern (Eds.), Governing europe's marine environment europeanization of regional seas or regionalization of EU policies? (pp. 163-181). Surrey, England: Ashgate.

Söderström, S., Kern, K., Boström, M., \& Gilek, M. (2016). 'Environmental governance' and 'ecosystem management': Avenues for synergies between two approaches. Interdisciplinary Environmental Review, 17(1)

Tynkkynen, Nina. 2014. Russia and the Baltic Sea: Frames and Spaces of Environmental Problems. Eurasian Geography and Economics 55 (6): 674-690.

van Leeuwen, J., L. van Hoof, and J. van Tatenhove. 2012. Institutional Ambiguity in Implementing the European Union Marine Strategy Framework Directive. Marine Policy 36 (3): 636-643. 
van Leeuwen, Judith and Kristine Kern. 2013. The External Dimension of European Union Marine Governance: Institutional Interplay between the EU and the International Maritime Organization. Global Environmental Politics 13 (1): 69-87.

van Leeuwen, Judith, Katrine Soma, and Jan van Tatenhove. 2015. Editorial Marine Governance in European Seas: Processes and Structures of Regionalization. Ocean \& Coastal Management 117: $1-3$.

van Tatenhove, Jan, Jesper Raakjaer, Judith van Leeuwen, and Luc van Hoof. 2014. Regional Cooperation for European Seas: Governance Models in Support of the Implementation of the MSFD. Marine Policy 50: 364-372.

Vangas, Alf. 2010. Can the EU Strategy for the Baltic Sea Region Bridge the 'Great Divide'? In EU Strategy for the Baltic Sea Region. A Year After and Beyond, edited by Žaneta Ozolina, Iveta Reinholde and Tom Rostoks, 103-119: Riga: Zinātne.

Wang, Hanling. 2004. Ecosystem Management and its Application to Large Marine Ecosystems: Science, Law, and Politics. Ocean Development \& International Law 35 (1): 41-74.

Wenzel, Bertholt. 2011. Environmental Governance and Institutional Interaction in the Baltic Sea Region: Effective Governance System or Institutional Entanglement? Master Thesis, Philipps University Marburg.

Wenzel, Bertolt. 2016. Organizing Coordination in a Public Marine Research and Management Advice Organization: The Case of the Norwegian Institute of Marine Research. Marine Policy 64: 159-167.

WFD. Directive 2000/60/EC of the European Parliament and of the Council of 23 October 2000 Establishing a Framework for Community Action in the Field of Water Policy (Water Framework Directive), (2000)

Young, Oran R. 2002. Institutional Interplay: The Environmental Consequences of Cross-Scale Interactions. The Drama of the Commons: 263-291. 